\title{
ELECTRIC VEHICLE HOUSEHOLD CHARGING BEHAVIOUR IN IRELAND AND AIMS FOR A CARBON NEUTRAL ELECTRIC FLEET BY 2020
}

\author{
Patrick Morrissey, Peter Weldon and Margaret O’Mahony
}

Trinity Centre for Transport Research and Innovation for People (TRIP), Department of Civil, Structural \& Environmental Engineering, Trinity College Dublin, the University of Dublin, Dublin 2, Ireland. Tel: +353 18962084 .

Email: morrispj@tcd.ie, weldonp@tcd.ie, margaret.omahony@tcd.ie

\section{Biographical Notes:}

Dr Patrick Morrissey is an environmental engineer currently working in consultancy. He holds undergraduate and master's degrees in civil and environmental engineering from Trinity College Dublin, the University of Dublin, Ireland, as well as a doctorate which he completed in 2013. Patrick worked as a post-doctoral researcher on the Green eMotion Eurpoean electromobility project; analysing electric vehicle (EV) user behavior, usage patterns and the impacts of mass EV roll-out across Europe. Patrick pursues a number of research interests in the areas of; renewable energy, smart grids, sustainable wastewater treatment systems and groundwater with a focus on numerical modelling techniques and statistical analysis.

Peter Weldon is pursuing a PhD in Civil, Structural and Environmental Engineering in Trinity College Dublin, the University of Dublin, Ireland, which is due to culminate at the end of 2015. He received his B.A. and B.A.I. degrees in Civil, Structural and Environmental Engineering from Trinity College Dublin, Ireland, in 2012 and a Postgraduate Diploma in Statistics in 2013. From 2012 until 2015 he worked on the EU funded Green eMotion FP7 project, focusing on the widespread deployment of electric vehicles throughout Europe. His research interests include electric vehicles and statistical data analysis.

Margaret O'Mahony is Professor of Civil Engineering (1842) and Director of the Trinity Centre for Transport Research and Innovation for People (TRIP) at Trinity College Dublin (TCD), the University of Dublin. A graduate in civil engineering from the National University of Ireland at Galway (NUIG), she holds a Doctorate in Engineering Science from the University of Oxford. She is a Chartered Civil Engineer, CEng FIEI, and a Fellow of TCD. She has led a large number of interdisciplinary research projects, funded by the EU and other national research programmes. They focus on transport policy, energy in transport, electric vehicles, transport planning, network modelling, optimisation of transport networks, demand management, transport pricing, urban freight solutions, vehicle instrumentation and innovative road materials. She is author of over 100 publications.

Key words: Electric vehicle, charging behaviour, carbon neutral. 


\begin{abstract}
Due to limitations on the supply and availability of fossil fuels and the need to reduce environmentally damaging emissions, the Irish government is attempting to increase the market share of electric vehicles (EVs) to a target of $10 \%$ by 2020 whilst also increasing the proportion of renewable energy generation. This paper uses data collected from household charge points in Ireland to analyse existing EV charging profiles, which formed part of the European Union funded Green eMotion project, and some useful results are found e.g. charging profiles for current Irish EV users show a large peak during the evening beginning near the current peak power demand on the electrical grid. The potential impacts of increased numbers of EVs in the population on the Irish electrical grid are assessed if EV penetration levels were to increase to different levels in the population. To assess a number of scenarios for projected levels of EVs into the population, the 2011 census database was used to examine the key demands of the population in terms of their car based work trips. A large proportion of Irish households were identified as being suitable for the purchase of an EV on this basis and a number of market penetration scenarios to 2020 are investigated. The next step in the research examined the potential impact on the electrical grid of the potential charging demand for the projected scenarios. The projected supply capacity within the Irish electrical grid would appear sufficiently capable to absorb the likely power demand from EVs in both 2016 and 2020 scenarios.
\end{abstract}

\title{
INTRODUCTION
}

Due to the size and location of Ireland and along with its tremendous potential to generate large amounts of electricity from renewable sources, particularly wind power, Ireland is uniquely placed to become a model for EV integration, with an efficient and clean transport network powered by renewable sources. As Ireland's largest energy provider, the Electricity Supply Board (ESB) is endeavouring to develop a nationwide infrastructure capable of fully supporting the number of EVs planned for Irish roads, primarily through their "ecars" initiative (ESB, 2014). The planned nationwide infrastructure is intended to support the Irish government's target of 250,000 EVs in the general vehicle fleet by 2020 (DCENR, 2008).

In order to achieve this task, almost 1,000 publically accessible charge points have been installed in Ireland up to the end of 2013, with the infrastructure continually expanding. Every town in Ireland with a population greater than 1,500 people will have a minimum of one charge point available to EV users. Fast chargers are being installed across the nation's motorways to create "electric highways" between major urban centres, and 50 of these fast charge points have already been installed up to the end of 2013. The infrastructure is being developed from research and infrastructural funding from the European Commission along with direct investment from the ESB. In addition, the Irish government are allowing the first 2,000 citizens to adopt an EV to avail of home charge point installation free of charge.

This paper reports on a trial to examine the behaviour of EV users in Ireland and to examine the impact on the electrical grid of different EV penetration rates into the Irish car fleet projected for different economic growth scenarios. The research questions, on which the paper reports, include examining the charging profiles of 72 users who each used one of 7 test vehicles, supplied by the ESB of Ireland, for a period of 4 months, to observe in real-terms how individuals use and charge 
EVs. This data collection and analysis formed one of a number of user behaviour trials of EVs across Europe, part funded by the European Union on the Green eMotion project. Green eMotion (Green eMotion, 2015) was a pan-European project aimed at developing the European framework for an interoperable electromobility system, beginning in March 2011 and concluding in February 2015. Once the charging profiles of the users had been observed in the Irish trial, the next step was to estimate how the electrical demand by EVs would scale up, as EV penetration increases in the Irish car market. To answer this research question, estimates of likely EV penetration were needed. To inform their selection, the 2011 Irish census data were analysed to profile the existing household population in Ireland in terms of car ownership levels and work car trip duration. The focus on these two characteristics was driven by the assumption that households having more than one car may be more likely to replace an existing vehicle in the household with an EV, that people may be more likely to purchase an EV if their roundtrip to work is well within battery range and finally the availability of this information in the census. (Very few questions with a transport focus are included in the Irish census form and this was a limiting factor in the analysis completed here). The next step in the process was to characterise the potential EV market penetration projections under a number of economic growth level scenarios. The final step in the work was to estimate the impact of the different EV penetration scenarios on the electrical grid in terms of charging demands and to assess the ability of the existing grid to cope with those demands.

The paper is laid out in the following way. The Background section includes a summary of relevant literature in the field. This is followed by a Methods section which is split into two sections. The first section focuses on the Green eMotion project and how the work presented here is related to that project. This section also describes the charging infrastructure and details the Irish electric vehicle behaviour monitoring trial along with a description of the variables measured. The second section covers the methods used in trying to estimate market penetration and demand drivers for a number of scenarios. This is followed by a Results section and the paper ends with a Conclusions section.

\section{BACKGROUND}

An Australian study using five weeks of driving data recorded by GPS technology found that (i) EVs with a range as low as $60 \mathrm{~km}$ and a simple home-charge set-up would be able to accommodate well over $90 \%$ of day-to-day driving, (ii) the incidence of tours requiring out-of-home charging increases markedly for vehicles below $24 \mathrm{kWh}$ (170 km range) and (iii) recharge time in itself has little impact on the feasibility of EVs because vehicles spend the majority of their time parked (Greaves et al, 2014). Households demonstrated that they can use the electric vehicle to make most of the everyday trips that were previously made in a conventional-fuel vehicle, but some trips will be shifted to other vehicles in the household's fleet (Golob and Gould, 1998).

The results from a trial of 135 drivers in the UK demonstrated that drivers were positive about recharging preferring it to conventional refuelling and they became more relaxed over time about the frequency of recharging (Bunce et al, 2014). A user-battery-interaction style and comfortable range were found to explain the charge level at which people typically charge using data from EV users (Franke and Krems, 2013a). Many EV users changed their opinion on experiential barriers after using the EV; charging duration and infrastructure, battery issues, and low noise level were 
less frequently reported as barriers after experiencing the EV (Buhler et al, 2014). Data from 79 participants who had driven an EV for 3 months indicated that higher average range needs, higher range of the driver's familiar combustion vehicle, and greater experienced range anxiety were related to higher range preferences (Franke and Krems, 2013b). They also found that range preferences decreased over the first 3 months of EV use.

A study of empirical driving profiles of eight socio-economic groups in Germany found that in the home charging case about $78.5 \%$ of all investigated profiles are feasible with the given EV, the Nissan Leaf (Schuller et al, 2014). Another study found that urban and rural vehicles have similar profiles, but the peak caused by rural vehicle charging is $19 \%$ greater than the urban vehicle peak (Kelly et al, 2012). They also found the highest income group had a $41 \%$ higher charging peak than the lowest income group. Research using a simulation tool found that (1) increasing home charging power above that provided by a common $15 \mathrm{~A}, 120 \mathrm{~V}$ circuit offers little added utility (2) workplace charging offers significant utility benefits to select high mileage commuters and (3) broadly available public charging can bring many lower mileage drivers to near-100\% utility (Neubauer and Wood, 2014).

A UK study investigating the recharging patterns of 12 private, 21 organization individual and 32 organization pool users over two successive six month periods found that less than $10 \%$ of recharging took place off-peak, work was the most popular location to recharge, and demand peaked between 09:00am and 10:00am. Private individuals' peak recharging occurred on an evening at home, while organization individual users recharged mostly during early morning at work. Recharging by organization pool users peaked at work during late afternoon (Robinson et al, 2012). Using simulation of a traffic network of EVs in MATLAB in other research, it was found that the total time due to the battery charging process was optimised at both the individual $\mathrm{EV}$ and the entire network level for EVs that were able to use connected vehicle communications (Johnson et al, 2013).

A study based in the province of Milan, Italy, used predicted EV market shares, real and estimated energy consumption, and electric power demand with the introduction of EVs, among other factors, to analyse the possible impact of EV drivers' recharging behaviours on the Milan electrical grid. Through the analysis it was found that without appropriate measures (such as the smart integration of EVs into the existing grid) EVs could heavily impact daily requested electric power, with the possibility of surpassing grid capacity dependent on the market penetration of EVs; within the model the capacity of the grid became greatly overloaded with the evening electrical demand of a 25\% fleet share of EVs (Perujo and Ciuffo, 2010). Additionally the timing at which charge demand on the grid peaks can vary depending on the location of the charging infrastructure and on the day of the week. In an analysis of real-data in the United States it was discovered that charging activity for personal-use vehicles was high from 04:00pm until 10:00pm, while for commercial-use vehicles demand peaks occurred between 02:00pm and 07:00pm, depending on the day of the week. This peak in demand was shifted to $10: 00 \mathrm{pm}$ on weekends for commercialuse vehicles (Smart et al, 2010).

The impacts of smart charging on the electrical grid were investigated by comparing the regions of Nashville and San Francisco in the United States, whereby Nashville residents have no timeof-use availability and San Francisco inhabitants have the option to choose time-of-use 
mechanisms. Using real-data from an EV trial, the results showed that charging demand on the electrical grid peaked in Nashville at 20:00 in the absence of time-of-use capabilities, whereas a large increase in demand was shown at 00:00 in San Francisco, which is the start of the off-peak time-of-use period, and demand peaked at 01:00 (Schey et al, 2012). In an additional study on smart charging based in the Netherlands using stochastic modelling of the power demand of EVs, it was found that, under $10 \%$ and $20 \%$ penetration scenarios, if all vehicles began charging at the instant off-peak charging became available, an additional load would affect the grid, but with added smart control by electrical utilities the demand could be uniformly distributed over the time period resulting in peak load reductions (Lojowska et al, 2012).

\section{METHODS}

\section{EV Charge Point and Vehicle Data Collection and Analysis}

The Green eMotion (Green eMotion, 2015) was a pan-European project aimed at developing the European framework for an interoperable electromobility system, beginning in March 2011 and concluding in February 2015. The project involved a consortium of 43 partners from all electromobility stakeholder groups, and had a total budget of $€ 42$ million (approximately $\$ 56.4$ million) with $€ 24$ million (approximately $\$ 32.3$ million) funded by the European Commission. In order to test and demonstrate the interoperability of an integrated electromobility system in Europe, demonstration regions were selected and set up in a variety of European countries, with Ireland being one of these demonstration regions. Fleets of vehicles and an abundance of charging infrastructure were deployed in each of the demonstration regions with the intention of recording, monitoring, and analysing the trip- and charge-making behaviours of EV users. The data collected and analysed for Ireland forms the basis for the user behaviour analysis presented in this paper.

Within the Irish demonstration region of the Green eMotion project, a total of 229 charge points were installed and monitored during the project. The monitored charge points originate from a variety of manufacturers and represent three charge point use cases: household charge points, onstreet public charge points, and workplace charge points. The focus of this study is on household charge points, of which sixteen were monitored during the analysis period, and all of these charge points were manufactured by Bespoke.

Household charge point installation began in 2011. They operate using Mode 1 charging which consists of slow charging from a regular electrical socket and with a single-phase power supply. The input and output nominal voltage of the charge points is $230 \mathrm{~V}$; the input and output nominal current is 13A; and the input and output nominal power is $3 \mathrm{~kW}$. As such, the household charge points take longer to charge vehicles than most public charge points, but since EVs are likely to be stationary for longer periods of time this is deemed to be acceptable for household charge points.

Within the Irish demonstration region, fifteen Mitsubishi i-Miev vehicles were deployed by the ESB, of which seven were private use vehicles and seven business use vehicles. The private use vehicles are the focus of this study, and they were offered to electric vehicle enthusiasts for four month trial periods. The ESB offered the vehicles to individuals so that real data could be collected on how individuals would use the EVs, to subject the charging facilities to real-world testing, to 
obtain feedback from the participants on the EVs and charging units, and to highlight the potential of EVs to the public (several national media events were arranged around the trial). Participants were selected through an application process via various forms of advertising; the trial attracted tens of thousands of applicants. During a successful applicant's four month trial period, a household charger was installed in their home and both the vehicle and the charge points were fitted with data loggers to record their trip- and charge-making behaviours.

The period during which data was collected from the household charge points was from May 2011 until February 2012 - following this period the focus of analysis was shifted to public and workplace chargers. Data was collected from charge points whenever a "charge event" occurred, which is defined as an event where an electric vehicle is plugged into a charge point and energy is being drawn from the charge point and delivered to the electric vehicle. Each charge point was assigned a unique ID in order to facilitate usage comparisons between each charger. Data from the charge points were transmitted via GPRS whenever a charge event was completed, and the data are managed by the ESB.

Once a charge event was detected by a charge point, parameters of data related to the charge event were measured and recorded by the data loggers. The following categories of data were recorded (the metrics used for each category of data are given in square brackets):

- Charge Start Time [hh:mm:ss]: the charge start time records the instance of power flow from the electricity supply to an EV.

- $\quad$ Charge Finish Time [hh:mm:ss]: the charge finish time records the instance power ceases to flow from the electricity supply to an EV.

- $\quad$ Charge Consumption [kWh]: the charge consumption is the total amount of energy consumed by an EV from a charge point during a charge event.

- Charge Duration [minutes]: the charge duration records the amount of time an EV is charging when connected to a charge point during a charge event.

The household charging profiles are analysed and used to estimate the impact on the electric grid under a number of potential EV market penetration scenarios to 2016 and 2020. An estimate is then made as to what proportion of the EV energy demand in those years could be delivered by renewable energy sources.

\section{EV Market Incentives and Demand Drivers}

In attempting to model the projected future EV penetration into the Irish market, the conditions and characteristics of Norway's successful EV programme were examined. Driven primarily by ambitious goals for reducing greenhouse gas emissions, the Norwegian government offers a range of incentives to promote EV sales. They include no vehicle registration tax (VRT), the lowest annual licence fee of $52 €(\$ 70)$, lower imposed benefit taxation for company cars, an increased mileage allowance rate, exemption from value added tax (VAT), access to bus lanes, road toll exemption, and free parking without free charging (TOI, 2013). In Ireland, the incentives include a zero rate of VRT, an initial purchase grant of $€ 5,000(\$ 6,737)$ and reduced annual road tax of $€ 120(\$ 162)$ year. While it might be difficult to offer the other more economically advantageous Norwegian incentives in Ireland in the current economic conditions, only the practical consideration of control would need to be dealt with in the case of offering use of bus lanes, free 
parking, and free road tolls (Ireland has less tolling operations than Norway so the economic disadvantage to the country would not be highly significant particularly in the early adoption phase).

Although the gap in incentives between the two countries is relatively large, the similarities are closer when looking at transport demand characteristics. In identifying the basis for the market for EVs in Norway, a study on electromobility (TOI, 2013) determined that $85 \%, 80 \%$ and $75 \%$ of daily mileage for car drivers was less than $80 \mathrm{~km}$ for those households with one, two or multiple cars, respectively. In the case of Ireland, the census covers only the main work trip rather than daily mileage and asks for trip duration (in minutes) rather than the distance of the trip in kilometres. For one, two, three and four+ car households, the percentage of households with oneway work trips less than 30 mins are $79 \%, 73 \%, 76 \%$ and $75 \%$, respectively.

Also noted in the Norwegian study was the fact that EVs are bought largely ( $90 \%)$ to replace a second vehicle in the household. Forty two percent of Norwegian households $(635,000)$ (Vagane, 2013) own 2 or more cars compared with 59\% of households $(1,644,176)$ in Ireland (CSO, 2012). The Irish travel survey found that trips made by car increase from $62 \%$ in city areas to $79 \%$ in rural areas (National Transport Authority, 2013). It also found that the average work and business trip was $15 \mathrm{~km}$ compared with $16 \mathrm{~km}$ in Norway (Vagane, 2013), the average of leisure trips was $13 \mathrm{~km}$ and shopping trips $7 \mathrm{~km}$.

Other research (Hjorthol, 2013) found that early adopters in Norway live in or near metropolitan areas and belong to households with more than one car. Using the CSO POWSCAR database (CSO, 2012), the distribution of households owning more than one car in Ireland was determined and is presented in Figure 1. Although the actual values might appear to show significant differences in the distribution across the country, normalisation to ratios in the figure insert shows less difference with perhaps a marginally higher rate of 2+ car households in urban areas.

Figure 2 presents the distribution of work trip duration in minutes for the households shown in Figure 1. Assuming typical commuting speeds, the potential for EVs to cover a large percentage of trips in each of the categories is high with almost all areas showing $80 \%$ - 90\% of trips less than 30 mins.

The next step is to examine what the market penetration rate might be into the future. Irish EV market sales this year are indicating a penetration level of $0.25 \%$. Long range forecasts for EV market penetration, given the major changes going on in the field, are likely to be fraught with error and so we only look at a range between low to high growth forecasts over the next 5/6 years to 2020. Market penetration in some of the literature refers to the levels of penetration into new car sales and this is the definition we use here as opposed to penetration levels into the entire car fleet.

One study (Propfe et al, 2013) used a model to project EV market penetration in Germany to 2020 and 2030 for three scenarios: 1) business as usual (BAU);2) an accelerated market condition scenario which includes the assumptions that oil prices increase faster than in the BAU case, that electricity prices reduce and that government EV purchase incentives are introduced; and 3) a car manufacturer mark-down scenario whereby EV cars are competitively priced against other 
vehicles. Guided by the findings of this work, penetration into new car sales for three of the scenarios to be tested here are assumed to be $0.42 \%, 2.6 \%$ and $10.1 \%$ in 2020 with a linear rise towards that rate for the intervening years. We will also consider the 2013 market penetration rate in Norway of 5.6\% in 2013 (Hjorthol, 2013) and apply this rate per year to 2020. A fifth scenario assumes the EV penetration rate in 2014 in Ireland to date of $0.25 \%$ is maintained each year to 2020 and finally we include a scenario that represents the previously discussed goal of the Irish government to have $10 \%$ of all cars in Ireland in 2020 running on electricity, amounting to 250,000 EVs.

The fluctuations in yearly car sales in Ireland over the last few years make it difficult to estimate yearly car sales to 2020. Due to the lack of a stable historical trend (because of a significant drop in car sales in recent years) three base levels of car sales for 2014, rather than one, are assumed: Low: 80,000, Medium: 85,000 and High: 91,500 (the latter assumes the same \% increase on 2013 figures is exhibited for the remainder of 2014 as in the first half of the year). For future projections year on year, we will keep the low sales level the same for all six years. We will apply a $1 \%$ increase in car sales, year on year, to the medium condition and $1.15 \%$ to the high condition. This will result in projected car sales in 2016 of 80,000 for low, 102,850 for medium and 121,000 for the high condition. For the year 2020, sales will be 80,000 for low, 150,580 for medium and 211,650 for the high condition; the latter being 30,000 short of the highest level of car sales at the top of the economic boom in Ireland in 2007, a level that economic commentators are saying is unlikely to be reached again in the short to medium term. It should be noted that there remains a strong desire amongst young people in Ireland to purchase a car and the car club/sharing model evident in some European cities has yet to be a significant factor in Ireland, except perhaps in some parts of central Dublin. For the Irish government's target, we use the same assumption as the EPA (EPA, 2011) that total car registrations will stabilise out to 2020. We therefore use the 2012 total car registrations of 1,887,710. The estimated numbers of EV population in 2016 and 2020 for each of the scenarios are presented in Table 1 for the low, medium and high growth conditions. A selection of the outcomes of the scenarios are evaluated in terms of the potential impact on the grid in the next section.

\section{RESULTS}

The charge point data collected at each of the monitored charge point installations were analysed and a total of $673 \mathrm{EV}$ daily charging profiles were extracted from the dataset. It should be noted that the participants could be described as EV enthusiasts and that the sample is relatively small. Therefore some caution is warranted in terms of interpreting the results. In order to assess the resulting load to the grid over both the 24 hour period and also over a full 7 day week, these daily charging profiles were first disaggregated into 24 hour charging profiles using the charge start and finish times and the charge consumption values. For the purposes of this analysis it was assumed that the power delivered to the EV was constant for the entire duration of the charge event and the charge consumption was spread over the associated hourly time slots on this basis. This dataset now containing 24 hour charging profiles was further divided into weekly charging profiles. A weekly charge profile was assumed to contain 4 or more charge registers over the 7 day period. For the purposes of maximising the dataset, weeks containing 3 charge registers were also included provided they were sufficiently spread out over the week. It should also be noted that it was common for individuals using the charge points to plug in their vehicles more than once per day 
and this trend has been frequently observed amongst early adopters beginning to use EVs since they would not be familiar with the capabilities of the batteries.

This disaggregation process resulted in 110 usable weekly charging profiles. Stacked area plots of the resulting charging profiles for each day of the week are shown in Figure 3(a) - (g). Also shown in Figure $3(\mathrm{~h})$ is a stacked area plot of the total summer/winter charging load to the grid from all of the charge points included in the dataset, with an insert showing the total weekly loading profile again from all of the monitored charge points. It can be seen that for each working day of the week (Monday - Friday) a large charging peak occurs in the period 16:00 - 22:00 accounting for 51.1\% of all charge energy consumption during weekdays. If the subsequent additional 2 hour period is also included, this figure rises to $72 \%$ of all charge consumption occurring between 16:00 - 00:00 with only $18.6 \%$ of charge energy consumption occurring in the 00:00 - 06:00 time period.

Weekend charging profiles are notably different to those observed for weekdays with charging spread out much further across the day and a more subdued evening peak. Charge energy consumption for the period 16:00 - 00:00 was 15.8\% lower than was seen for weekdays at $56.1 \%$ of the total. Daytime charge energy consumption (07:00 - 15:00) was also more prevalent. However, night-time charge energy consumption was similar to what was observed for weekdays at just $17.4 \%$ of the total. Peak power demand on the Irish electricity grid occurs in the time period 17:30 - 18:30 during winter months and it was seen that for weekday charging profiles $16.5 \%$ of all charge consumption was during this period of peak demand on the electricity grid. A large increase in numbers of EVs could have a significant impact on peak power demand should these charging patterns continue. Summer and winter charging profiles are similar, both over a 24 hour period and also over the full week, and therefore any load arising from increasing numbers of EVs connecting to the grid is likely to be constant throughout the year.

Forecasting the projected load to the energy grid arising from higher rates of penetration of EVs is not straightforward; however given the Irish government's ambitious targets for the entire EV fleet the future load from EVs has the potential to have significant impacts on Ireland's future electricity demand. Some tentative estimates have been made on what this future loading from EVs will be with EirGrid, the Irish state body with responsibility for the provision of transmission and market services for electricity consumers, estimating a daily charging load of 2,800 MWh from 250,000 EVs in 2020 (Eirgrid, 2011). EirGrid also uses a multiple linear regression model to calculate the Republic of Ireland's Total Energy Requirement (TER) and this model has been used to calculate the TER for 2020 for a number of growth scenarios which consider factors such as economic growth and changes in winter temperatures (Eirgrid, 2008). As part of this process, peak energy is also predicted and the peak energy demand for Ireland in 2020 has therefore been estimated in the range $5250-5550 \mathrm{MW}$.

The grid has been deemed capable of accommodating the energy load resulting from 250,000 EVs due to the assumption that by 2020 smart metering/charging will be prevalent and the majority of charging will occur between 00:00 - 06:00 when excess capacity exists in the grid. However smart metering/charging may or may not be widely available by 2020 and, in addition, the charging trends shown previously indicate consumers may prefer not to charge their vehicles at night even if smart charging were available. For these reasons the charging profiles observed during this study have been used together with the data available on future grid energy demand and capacity to 
estimate what the impacts to the grid would be should these charging profiles continue. These estimations were then used to evaluate the impacts on the grid given the EV sales' penetration scenarios for 2016 and 2020 as per Table 2. The Irish government also has ambitious targets set for renewable energy, particularly wind energy, with a commitment to achieving $40 \%$ renewables by 2020 resulting in an additional installed wind capacity of between 1,900 - 2,500 MW (Eirgrid, 2011). The potential of renewables for green energy supply with a view to achieving carbon neutrality for EV charging will also be estimated. Currently data is only available for wind generation and not renewable energy as a whole; however given that wind energy is likely to account for the majority of Ireland's renewable energy supply this will not impact the analysis significantly.

Power demand (MW), wind generation to the grid (MW), and EV power consumption (MWh) for the current EV penetration rate in 2014 have been plotted over a 7 day period in Figure 4 (a). A similar plot for the projected 2020 penetration rate for Scenario 4 (S4) under medium sales growth is given in Figure 4 (b) - power demand and wind generation have been scaled up using the 2014 profile and the EirGrid projected growth rates (Eirgrid, 2008). These plots were constructed by combining data from EirGrid power demand and wind generation records for a week in January 2014 (winter high demand conditions) with the charging profiles identified in Figure 3. It can be seen that the EV power demand profile follows the grid power demand very closely with very similar peaks.

In order to further investigate the potential impacts on the power grid from the various EV penetration scenarios shown in Table 2 it was necessary to make a comparison in terms of peak power demand as EV power has been assessed in terms of energy consumption thus far. In order to assess EV charge points in terms of power demand an assumption was made regarding the installed charge point power ratings. All future charge points were assumed to be Type 1 with a rated power of $3 \mathrm{~kW}$, which is conservative given that projections are being made to 2020 . Using this power rating, the peak power demand and wind generation for 2013 as a base (to which the appropriate growth rates were applied to 2020) values of peak power demand arising from EVs for each of the scenarios were calculated. The proportion of peak power demand attributing to each of the EV penetration scenarios was also calculated. The resulting values are presented in Table 2.

It can be seen that if the government's target of 250,000 EVs by 2020 is reached then EV charging will account for approximately $14 \%$ of peak power demand from the grid. It must be noted that for all other penetration rate scenarios EVs only account for a maximum of $3.2 \%$ of peak power demand. Given the projected growth rates in renewable power generation being added to the electrical grid, it is likely that for all penetration scenarios (including the government's target of 250,000 EVs by 2020) the entire power demand arising from EVs has the ability to be met with renewable energy. This would have the effect of creating an entirely carbon neutral fleet of vehicles which would have many health and air pollution benefits and would also potentially result in significant cost savings. EirGrid has estimated that by 2020 there will be an excess spare capacity in the grid of some 1,200 MW and therefore there would appear to be sufficient future spare capacity to cater for all of the projected EV penetration scenarios. 


\section{CONCLUSIONS}

Electric vehicles currently occupy a small share of the Irish market and aggressive government and car manufacturer strategies would need to be employed in order to meet a target $10 \%$ electromobility in Ireland by 2020 . Irish national census data indicates that there exists significant potential for consumers based in a majority of Irish regions considered in the analysis to substitute their conventional vehicle for an EV based on the current range of EVs and their likely commuting distances. Assuming that consumers from $2+$ car households are more likely to purchase an EV, a large target market exists in a great number of Irish regions analysed as the proportion of $2+$ car households in all areas is high. A number of different EV sales penetration profiles were investigated and a large variation in the projected market share for EVs was seen for 2016 and 2020.

Existing EV user data were analysed to observe weekly charging profiles and trends in these charging profiles have been identified. Night charging is not prevalent and the peak in charging events coincides with peak demand on the electrical grid, with this trend particularly evident for weekdays. Weekend charging profiles were more spread out over the day and peaks were not as evident. No significant seasonal differences in charging profiles were observed during the study; however the weekly energy consumption profile observed for EVs follows closely the weekly power demand profile from the electrical grid. Given the low levels of night charging observed during the study, it must be noted that the introduction of smart charging to allow EV charging at off-peak times would be desirable. The potential impacts of various EV penetration scenarios were investigated for peak power demand conditions in 2016 and 2020. The Irish electrical grid would appear to have not only the capacity to cater for all projected EV sales' scenarios using current charging profiles but it would also seem likely that the entire EV power demand can be met from renewable energy allowing for a completely carbon neutral electric fleet in 2020, provided the aforementioned goal of $40 \%$ renewable electricity generation is reached.

The results are relevant to policy makers in Ireland and other countries in terms of informing them about potential EV user charging behaviour, in particular, the periods during which users prefer to charge their vehicles. This type of information is useful in guiding policy makers in terms of smart charging policy making and also in the provision of incentives, monetary or otherwise, that might be useful in managing load on the grid. The results are also useful in providing information on the likely potential for renewable energy to satisfy EV demands on the basis of future projected growth scenarios. A limitation of the work is the size of the trial which is a function of the expensive and resource intensive monitoring needed to capture user behaviour in a real-world context.

\section{ACKNOWLEDGEMENTS}

The authors would like to acknowledge the support of the EU under the Green eMotion project and to thank the ESB for their substantial support with the research and for allowing use of the data. The authors would also like to acknowledge SIEMENS and IREC in their roles in Green eMotion, and the Irish Central Statistics Office for use of the census POWSCAR data. 


\section{REFERENCES}

Bühler, F., P. Cocron, L. Neumann, T. Franke, and J. F. Krems. (2014). Is EV experience related to EV acceptance? Results from a German field study. Transportation Research Part F: Traffic Psychology and Behaviour, Vol 25, Part A, pp. 34-49

Bunce, L, M. Harris, and M. Burgess. (2014). Charge up then charge out? Drivers' perceptions and experiences of electric vehicles in the UK. Transportation Research Part A: Policy and Practice, Vol. 59, pp. 278-287.

Central Statistics Office (CSO) of Ireland. (2012). Census of population of Ireland 2011 place of work, school or college. Census of anonymised records (POWSCAR) database. 2012. Swords, Dublin.

Central Statistics Office (CSO) of Ireland.(2013). CSO Statistical Yearbook 2013. http://www.cso.ie/en/releasesandpublications/statisticalyearbookofireland/statisticalyearbookofir eland2013edition/ Accessed Jun 28, 2015.

DCENR. (2014). Government announces plans for the electrification of Irish motoring. Department of Communications, Energy and Natural Resources, Dublin, Ireland. November, 2008. L

http://www.dcenr.gov.ie/Press+Releases/2008/Government+announces+plans+for+the+electrific ation+of+Irish+motoring.htm Accessed June 28, 2015.

EirGrid. (2008). Generation Adequacy Report 2009-2015. EirGrid Plc., The Oval, 160 Shelbourne Road, Ballsbridge, Dublin 4, Ireland

EirGrid. (2011). All-Island Generation Capacity Statement 2012-2021. EirGrid Plc., The Oval, 160 Shelbourne Road, Ballsbridge, Dublin 4, Ireland

EPA (2011). Ireland's Greenhouse Gas Emissions Projections. 2010-2020. Dublin, Ireland.

ESB. (2015). ESB ecars project website. http://www.esb.ie/electric-cars/ Accessed June 28, 2015

Franke, T., and J. F. Krems. (2013a). Understanding charging behaviour of electric vehicle users. Transportation Research Part F: Traffic Psychology and Behaviour, Vol. 21, pp. 75-89.

Franke, T., and J. F. Krems. (2013b). What drives range preferences in electric vehicle users? Transport Policy, Vol. 30, pp. 56-62.

Golob, T.F., and J. Gould. (1998). Projecting use of electric vehicles from household vehicle trials Transportation Research Part B: Methodological, Vol. 32, Issue 7, pp. 441-454.

Greaves, S., H. Backman, and A.B. Ellison. (2014). An empirical assessment of the feasibility of battery electric vehicles for day-to-day driving. Transportation Research Part A: Policy and Practice, Vol. 66, pp. 226-237 
Green eMotion. (2014). Green eMotion project website. http://www.greenemotion-project.eu/. Accessed July 28, 2015.

Gronnbil.(2014). Over 20,000 ladbare biler pa norske veier.

http://www.gronnbil.no/nyheter/over-20-000-ladbare-biler-paa-norske-veier-article366239.html. Accessed June 28, 2015.

Hjorthol, R. (2013). Attitudes, ownership and use of Electric Vehicles - a review of literature. TØI Report 1261/2013. COMPETT, Work Package 2 Report. Transportøkonomisk institutt, Austrian Energy Agency, Vejdirektoratet Denmark.

Kelly, J. C., J. S. MacDonald, and G. A. Keoleian. (2012). Time-dependent plug-in hybrid electric vehicle charging based on national driving patterns and demographics. Applied Energy. Vol. 94, pp. 395-405.

TOI (2013). Electromobility in Norway - experiences and possibilities with electric vehicles. TOI, Institute of Transport Economics. Oslo.

Johnson, J., M. Chowdhury, Y. He, and J. Taiber. (2013). Utilizing real-time information transferring potentials to vehicles to improve the fast-charging process in electric vehicles. Transportation Research Part C: Emerging Technologies, Vol. 26, pp. 352-366.

Lojowska, A., D. Kurowicka, G. Papaefthymiou, and L. van der Sluis. (2012). Stochastic Modelling of Power Demand Due to EVs Using Copula. IEEE Transactions on Power Systems, Vol. 27(4), pp. 1960-1968.

National Transport Authority (NRA) (2013). National Transport Authority National Household Travel Survey. 2013. http://www.nationaltransport.ie/wp-content/uploads/2013/10/HouseholdTravel-Survey-Full-Report-July-2013.pdf

Neubauer, J., and E. Wood. (2014). The impact of range anxiety and home, workplace, and public charging infrastructure on simulated battery electric vehicle lifetime utility. Journal of Power Sources, Vol. 257, pp. 12-20.

Robinson, A.P., P.T. Blythe, M. C. Bell, Y. Hübner, and G. A. Hill. (2012). Analysis of Electric Vehicle Driver Charging Behaviour and Use of Charging Infrastructure, Proceedings of the 18th World Congress on Intelligent Transport Systems. CD-ROM.

Perujo, A., and B. Ciuffo. (2010). The Introduction of Electric Vehicles in the Private Fleet: Potential Impact on the Electric Supply System and on the Environment. A Case Study for the Province of Milan, Italy. Energy Policy, Vol. 38(8), pp. 4549-4561.

Propfe, B, Kreyenberg, D., Wind, J. and Schmid, S. (2013). Market penetration analysis of electric vehicles in the German passenger car market towards 2030. International Journal of Hydrogen Energy, 38, 5201-5208. 
Schey, S., D. Scoffield, and J. Smart. (2012). A First Look at the Impact of Electric Vehicle Charging on the Electric Grid in The EV Project. Presented at EVS26 International Battery, Hybrid and Fuel Cell Electric Vehicle Symposium. Los Angeles, CA, May 6-9.

Schuller, A., and J. Hoeffer. (2014).Assessing the Impact of EV Mobility Patterns on Renewable Energy Oriented Charging Strategies. Energy Procedia 46, pp. 32 - 39.

Smart, J., J. Davies, M. Shirk, C. Quinn, and K. S. Kurani. (2010). Electricity Demand of PHEVs Operated by Private Households and Commercial Fleets: Effects of Driving and Charging Behavior. Presented at EVS25 The $25^{\text {th }}$ World Battery, Hybrid and Fuel Cell Electric Vehicle Symposium and Exhibition, Shenzhen, China, November 5-9.

Vågane, L. (2013). Den nasjonale reisevaneundersøkelse 2009 - Egne kjøringer for reiselengder flerbileiere. Oslo, Transportøkonomisk institutt. 
TABLE 1 Predicted EV penetration rate scenarios

\begin{tabular}{|c|c|c|c|c|c|c|}
\hline & $\begin{array}{c}\text { Scenario } \\
1\end{array}$ & $\begin{array}{c}\text { Scenario } \\
2\end{array}$ & $\begin{array}{c}\text { Scenario } \\
3\end{array}$ & $\begin{array}{c}\text { Scenario } \\
4\end{array}$ & $\begin{array}{c}\text { Scenario } \\
5\end{array}$ & $\begin{array}{c}\text { Scenario } \\
6\end{array}$ \\
\hline & $0.25 \% / \mathrm{yr}$ & $0.07 \% / \mathrm{yr}$ & $0.43 \% / \mathrm{yr}$ & $1.68 \% / \mathrm{yr}$ & $5.60 \% / \mathrm{yr}$ & $\begin{array}{c}10 \% \text { entire } \\
\text { fleet }\end{array}$ \\
\hline & $\begin{array}{c}\text { Current Irish } \\
\text { Market } \\
\text { Penetration } \\
\text { Rate }\end{array}$ & $\begin{array}{c}\text { BAU case } \\
\text { (Propfe et al, } \\
\text { 2013) }\end{array}$ & $\begin{array}{c}\text { Accelerated } \\
\text { market } \\
\text { condition } \\
\text { scenario (Propfe } \\
\text { et al, 2013) } \\
\end{array}$ & $\begin{array}{c}\text { Car manufacturer } \\
\text { mark down } \\
\text { scenario (Propfe } \\
\text { et al, 2013) }\end{array}$ & $\begin{array}{c}\text { Norwegian market } \\
\text { penetration rate in } \\
2013 \\
\end{array}$ & $\begin{array}{c}\text { Irish } \\
\text { Government's } \\
\text { Target }\end{array}$ \\
\hline \multicolumn{7}{|l|}{2016} \\
\hline Low & 887 & 655 & 1,527 & 4,528 & 13,727 & \multirow{3}{*}{250000} \\
\hline Medium & 990 & 816 & 2,457 & 8,104 & 16,043 & \\
\hline High & 1,081 & 1,466 & 3,267 & 11,204 & 18,080 & \\
\hline \multicolumn{7}{|l|}{2020} \\
\hline Low & 1,687 & 1,663 & 7,767 & 28,772 & 31,647 & \multirow{3}{*}{250000} \\
\hline Medium & 2,303 & 2,712 & 14,202 & 53,730 & 45,446 & \\
\hline High & 2,819 & 4,384 & 19,775 & 75,332 & 56,993 & \\
\hline
\end{tabular}

TABLE 2 Potential power required from penetration scenarios

\begin{tabular}{|c|c|c|c|c|c|c|c|}
\hline Year & Scenario & $\begin{array}{c}\text { Power } \\
\text { Available } \\
\text { (MW) }\end{array}$ & $\begin{array}{c}\text { Renewable } \\
\text { Power } \\
\text { (MW) }\end{array}$ & $\begin{array}{c}\text { Power } \\
\text { Required } \\
\text { (MW) }\end{array}$ & $\begin{array}{c}\text { \% of } \\
\text { Power } \\
\text { Available }\end{array}$ & $\begin{array}{c}\text { Power } \\
\text { Required } \\
\text { (MW) }\end{array}$ & $\begin{array}{c}\text { \% of } \\
\text { Power } \\
\text { Available }\end{array}$ \\
\hline & & & & \multicolumn{2}{|c|}{ Medium } & \multicolumn{2}{|c|}{ High } \\
\hline 2020 & S1 & 5308 & 2813 & 6.91 & 0.13 & 8.46 & 0.16 \\
\hline & S2 & & & 8.14 & 0.15 & 13.15 & 0.25 \\
\hline & S3 & & & 42.61 & 0.80 & 59.33 & 1.12 \\
\hline & S4 & & & 161.19 & 3.04 & 226.00 & 4.26 \\
\hline & S5 & & & 136.34 & 2.57 & 170.98 & 3.22 \\
\hline & S6 & & & 750.00 & 14.13 & 750.00 & 14.13 \\
\hline
\end{tabular}




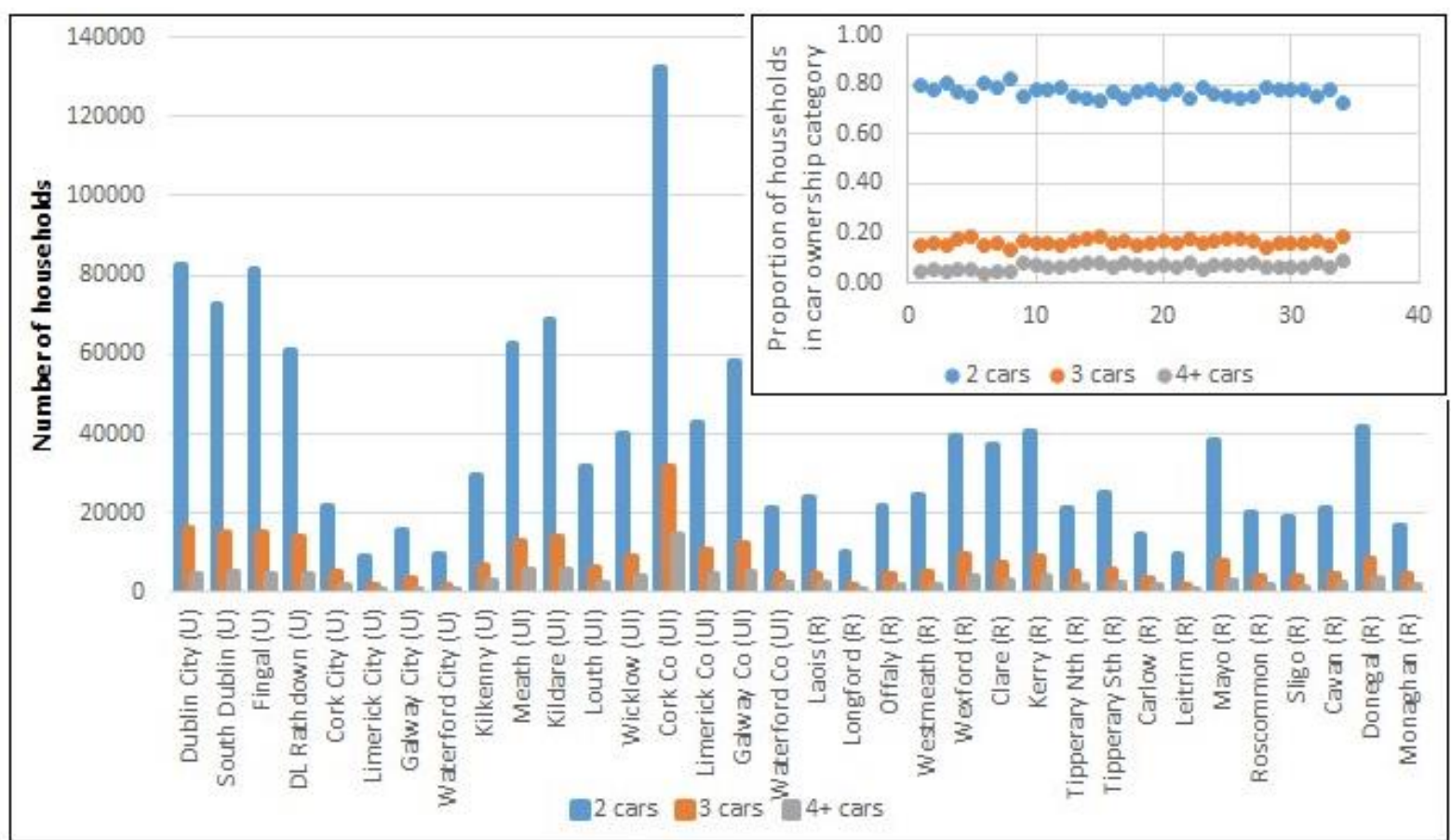

Note: $\mathrm{U}$ on the figure refers to urban areas, UI refers to areas which are close to cities (urban influence) and R refers to predominantly rural counties.

FIGURE 1 Distribution of households owning more than one car in Ireland 


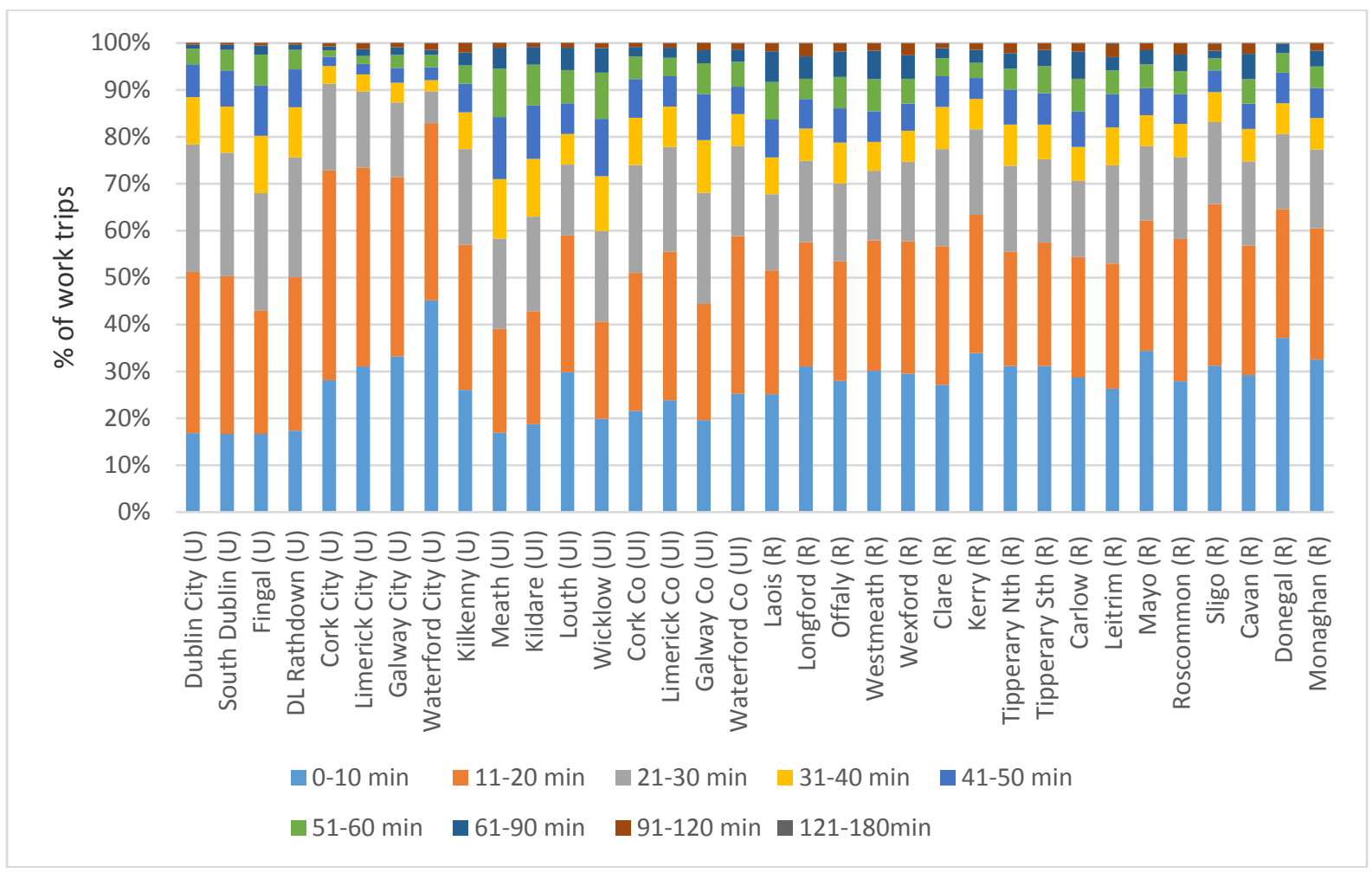

FIGURE 2 Distribution of work trip durations for 2+ car households in Ireland 


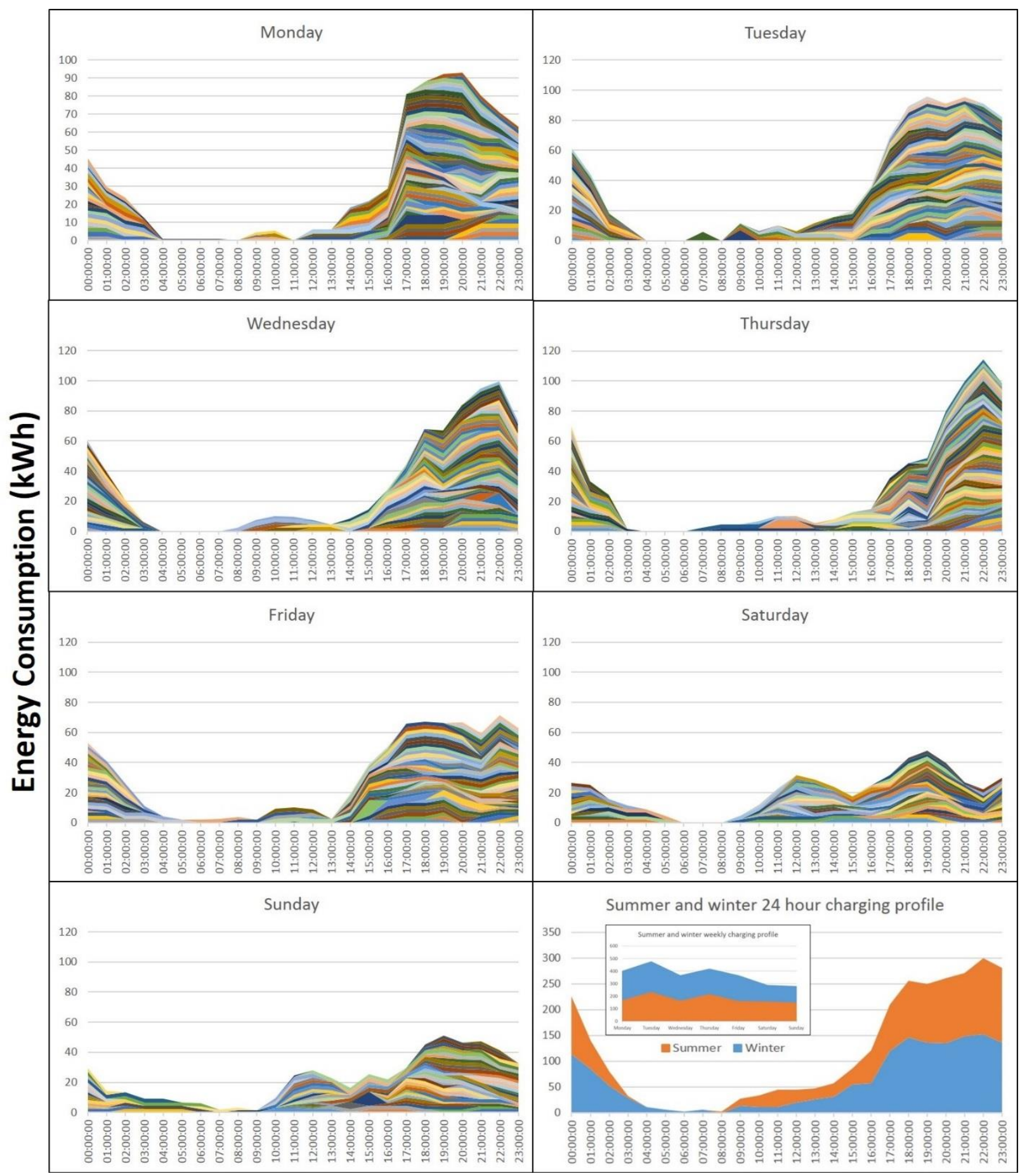

FIGURE 3(a) - (g) Stacked area plots of observed charging profiles for each day of the week; (h) Stacked area plot of summer/winter total charging profile load to the grid from the monitored charge points with weekly charging profile load to the grid shown on insert 


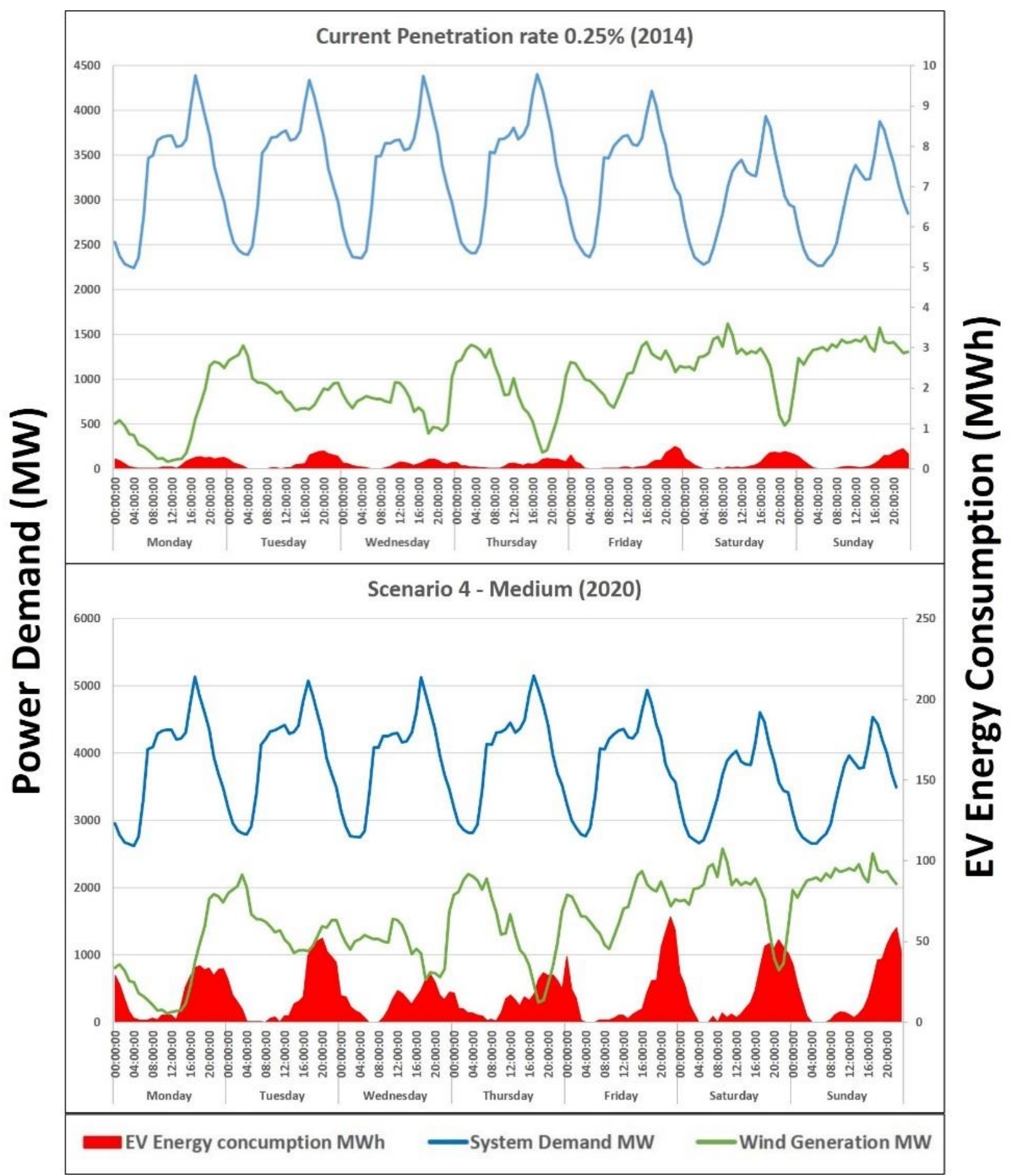

FIGURE 4 Plots showing the distribution of power demand and wind generation over a 7 day winter period, with the EV power consumption over a 7 day period also shown on a secondary axis. Current EV penetration and power situation shown on (a) with future projected Scenario 4 Medium penetration rates and 2020 power situation shown in (b) 